\title{
Cloud Services for Device Utilization and Optimization of Hybrid Network
}

\author{
AR.Arunachalam, G.Michael, R. Elankavi
}

\begin{abstract}
Network devices are labeled as one of the essentially hard tasked equipment. These devices are dynamically taking part in the network based on the user demand. Thus the network is updated with new devices, as well as the existing devices find their way to update themselves based on the network changes to provide network services to users. Erstwhile the existing devices in the network left offhand to provide services due to the drastic changes in the hybrid network updates such as operating systems and those devices face incompatibility. This examination distinguishes the most usable gadgets in the crossover coordinate with the assistance of genuine considerable system. Likewise it talks about the usable gadget's measurements as a gathering of comparable nature.The statistics includes the packet usage, protocols used for communications, error messages. This analysis recommends cloud based services to solve compatibility issues by analyzing network traffic hindrances. This experiment uses over all 1000 pcs, 100s of hybrid network devices and a network analyzer software for observation and to analyze the fixed term of network traffic packets among the devices. The investigation additionally recommends the required strides towards the reusability of existing gadgets to give nature of administrations to the clients in the half breed arrange condition by methods for cloud based patches.
\end{abstract}

Keywords: Virtual Network; Hybrid Network; Bandwidth; Device utilization

\section{INTRODUCTION}

The organizations have taken various measures and steps to follow or determine the needs in discovering of all the devices in a network[1],[3],[5]. It might include for other reasons such us compatibility issues and Quality of services for observing the devices that exist and part of the network. This research focus on the network devices that are particularly involve in impact on network traffic have been monitored and considered for the retention purposes and also the importance of providing the cloud based services to sustain those devices. In specific to these devices namely printers that face issues with compatibility or adapting the hybrid environment are to be considered for the future cloud based services[2],[4],[6].

There are observations that are made concern by the organization to retain the existing the devices and recommend cloud based solution for issues that are explained

\section{Revised Manuscript Received on July 22, 2019.}

Dr.AR.Arunachalam, Department of Computer Science and Engineering, Bharath Institute of Higher Education and Research, Chennai , India. Email: ararunachalam78@gmail.com

G.Michael, Department of Computer Science and Engineering, Bharath Institute of Higher Education and Research, Chennai, India. Email: micgeo270479@gmail.com

R. Elankavi, Department of Computer Science and Engineering, Bharath Institute of Higher Education and Research, Chennai, India. Email: kavirajcse@gmail.com before. It firstly, the association ought to consider the assets that are being gotten to at a specific time and by which individuals. This reduces potential usage by whom and the purpose of usages; it allows the organization to secure their network from drudger accessing the network resources or important information when it travels on the network[7],[9],[11]. Furthermore, the association ought to be in a situation to screen the system transfer speed and ensure that it isn't backed off by bundles sent by obscure sources. Additionally an association ought to think about simpler usage and allocating of various jobs to various gadgets in agreement to the association gauges. This ought to incorporate observing of programming introduced on various gadgets, their licenses and when they are expected to terminate so as to maintain a strategic distance from gadget deficiencies, and the adaptations introduced for these gadgets programming rather go for a cloud based answer for lessen the obstacle[8],[10],[12]. In conclusion, an association ought to consider arrange revelation gadgets that in the event of a system disappointment will effectively identify that of purpose of disappointment and right the system issue in time utilizing a similar administration that given by the cloud. The following section ropes in the common problem that exist in the network instigated by the devices especially printers.

Tools to curb the issues and the device faults

It is well pragmatic that many tools to curb issues that limit the network performance services reaching the destinations. Management software is often used to discover and monitor performance of network devices as an unabridged. Common functions of management software are detecting the devices and solve the compatibility issues to access the network by providing an updates[13],[15],[17].

Monitoring the various processes performed by a device by waiting for the device to send information about the required updates. It causes again the traffic impact on the network However, real devices grieve from drip [1,2]. The user uses these devices may or may not be aware of what these update is meant to give alert as it could be an update or just an alert that is unnoticed. Also software keeps track of those devices that are accessing the LAN remotely or locally. The traffic flow on the network rapidly increases which gives slow response to the device that need updates. Managing software used in a certain organization by keeping track of their license and the current versions of software being used.

These are the product could be open source or business programming. Components that decide the kind of programming to be utilized for system disclosure are explicit 
to the necessities of every association.

A few factors that ought to be considered ought to be; the size of the system and the measure of cash the association is eager to save[14],[16],[18]It is again leading to non-friendly network structure that provides no user friendly services. The entire above scenario escalating the importance of the cloud based service to provide the necessary updates to the devices such as printer to reduce the network traffic slowdown and to deliver the compatible resources to the network.

The question that causes printer on the system lead to stop up the traffic that need prompt considerations are referenced in the as pursues segment, Printing is excessively moderate, Windows is sending print occupations to the off-base printer, My prints are excessively light, excessively spotty, or have even lines, My printer says my ink cartridge is vacant, My paper plate is unstable [4] are a portion of the client saw issues and other may have progressively basic to note and streamline. Different issues with gigantic documents that are not upheld by the inner memory to hold with a wired association check whether printer underpins 100Base-T or gigabit Ethernet. Assuming this is the case, confirm that your switch and system can deal with those rates - in the event that they can't, you're making a bottleneck, particularly when sending designs overwhelming records to the printer [5]. You may need to burrow around to get the subtleties different printer producers give this data in various areas in the product. On the off chance that you don't see it in the driver programming, inquire in the manual [6]. This leads misperception; rather than having better elective cloud based administration is prescribed in this analysis. Then again Virtualization advancements have drastically changed the manner in which that we consider servers and system gadgets when all is said in done anyway numerous architects neglect to understand that these innovations have likewise made critical changes to our systems [7]. The system gadgets and offer countless administrations accessible to the client of course, likewise a noteworthy traffic generator over the system. Interestingly printers of yester-year, printers of today are generally organized and new mechanical attacks the more established printer left spur of the moment either gadget driver updates missing or the system is caused the traffic gradualness [8]. There are many research exercises fuelling to distinguish the system gadgets which are making the traffic all things considered in the network[9][10]. The printer is the gadget which is intently screen to improve the traffic by doing privately directed activity in an individual PCs those are unbinding NetBIOS, Network Access request and for expelling program traffic login contents maps to as often as possible utilized offers, and NT profiles can place organize proper printer object. The accompanying segment of the paper gives brief purpose for choice to this point by point printer probe the enthusiastic system.

\section{SCOPE}

The scope of this research is to identify the issues of the network devices for a particular organization through the network infrastructure. This study is representing printers as a most effective device that provides services to the user next to personal computers in an organization. The network efficiency is observed by running services, the protocols used for communications by the device printer is considered for analysis such as SNMP, DHCP, SSDP, UDP, TCP, NBNS, MDNS. Alongside the packet usage, protocols used for communications and error messages status and device statistics. Hence hastily justify that there necessary a cloud based patch service that optimizes the hybrid network devices performance.

\section{EXPERIMENTAL SETUP}

The fig 1,below demonstrates the system engineering of test bed which associate three noteworthy systems and four administration based systems[19],[21],[23]. These systems give instructive and learning the board administration more than 2500 understudies and the resources in the grounds. This comprises of LAN and the accompanying innovative setups. Additionally the system is plot as three bunches to give the instructive administrations. For the powerful organization and upkeep of this system benefits, the order and bunch made in the office level.

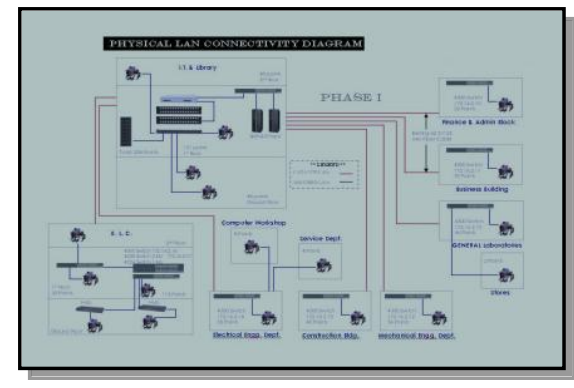

Figure 2 : Experimental Network Structure

The system configuration is built with most recent innovative peripherals with particulars, for example, cisco switches 4503E, SAN Switch IBM 2005 16B, cisco switches 1700,2800 arrangement; Firewall-CISCO-ASA-5510, cisco call director for IP telephones incorporate of CISCO-MCS-7800-KQGCY35, Pentium D 2.80GHz. It is in excess of 1000 hubs are normally Concentrated with UTP CAT-5, CAT-5E,CAT-6 and Fiber Channel switch made up of fiber multimode channels. The set up foundation coordinated with remote loyalty of different producers. The system is improved with Video conferencing upheld for entomb and intra conferencing office[20],[22],[24]. The system association additionally stretched out to reach VPN extranet. The client bolster gadgets provide food into top of the line organized HP and Xerox Laser fly printer and Photocopiers of different models. In this investigation, the system traffic of gadgets printer are observed on different time recurrence.

\section{RESULT AND DISCUSSIONS}

As the experiment began with the identification of list of devices on the network then collected information such as IP address and MAC addresses respectively to identify the devices as broad-spectrum. The software wireshark is used for analysing the data on the network. The devices' IP addresses are the parameter that is

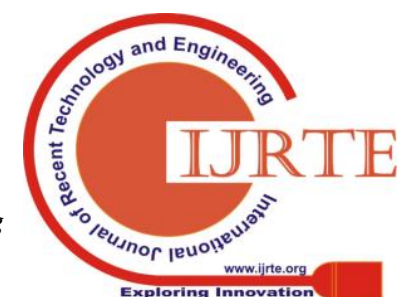


used for filter the traffic exclusively printer traffic and their impact in the network are analysed. The details acquired during the analysis based on bandwidth consumption details by the devices, comparison List of network printer, Total packets against used protocols that are connected to printer services, traffic impact by the devices.

The results are discussed in this section starting from complete devices' list to printers that are considered second biggest traffic contributor next to desktop computers. The Table-1 below shows the list of devices for last six years, it has increased exponentially. The ratio between the printer and the personal computers are nearly 1:3 of the device increased from the starting point to the end for a period of time. The device printer has shown better growth among the other network devices. For the experiment purpose only active device at the ultimate office hours is considered for analysing the data. The Table- 1 also depicted the only major devices that are used in an organizational environment.

It is also been depicted in the below fig 2 . The legends in the fig 2, are promptly seen and it is clearer that the optimization support needed for the device printer since these devices' traffic also has an impact on the network quality of services.

Table 1. Over all device statistics

\begin{tabular}{|c|c|c|c|c|c|c|}
\hline Rescurces/years & 8 & $\frac{1}{8}$ & 8 & $\stackrel{\mathrm{O}}{\mathrm{O}}$ & $\stackrel{\vartheta}{\varrho}$ & 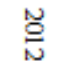 \\
\hline Computers & 628 & 762 & 812 & 992 & 1024 & 1151 \\
\hline Printers & 69 & 87 & 126 & 129 & 137 & 167 \\
\hline Photocopiers & 16 & 14 & 27 & 41 & 33 & 44 \\
\hline
\end{tabular}

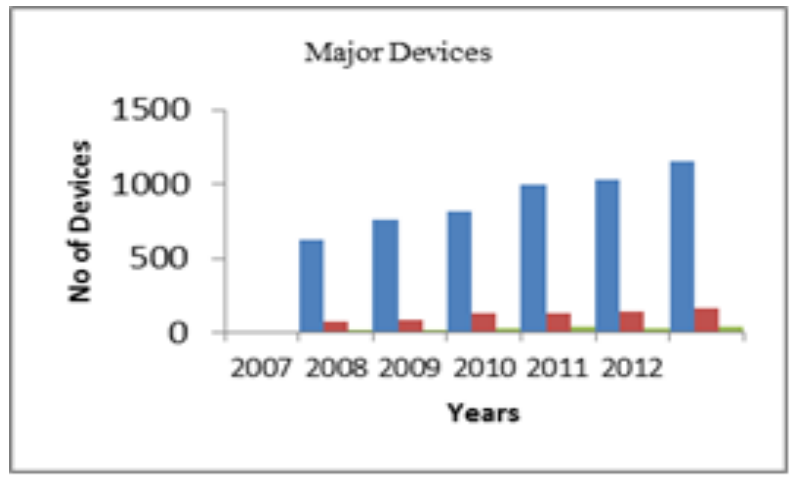

Figure 1- Over all device statistics

In addition to this optimization result analysis, the other devices are also given equal important. The printer appears to be second largest network device that pact influence on the network traffic[31],[33],[35]. This ensures that there need to be a cloud based service that cares the considerable amount of printers in the network. The following section discusses the traffic impact on the network by printers.

Table 2. Printer used packets statistics

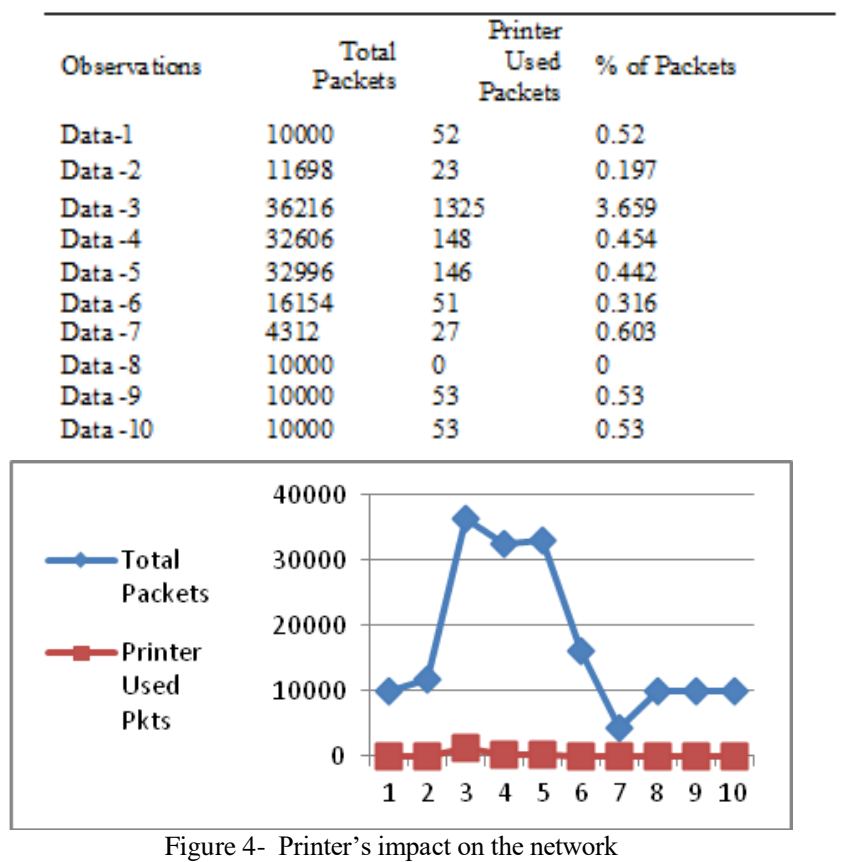

As discussed earlier, the network capable printer could create kiosk in the network traffic. The analysis depicted above indicates the data from various observations and the packet captured by the analytical tools. The table2, shows the frequency at the data-3 the printer has used the maximum of 1325 packets as compared with their Counterpart PCs and other devices in the network that create network traffic, Fig 3., depicted the variation of the printer impact on the network at different time interval as it is captured by the tool.

Table 4. Protocols used for managing device printers

\begin{tabular}{|c|c|c|c|c|c|c|c|c|}
\hline $\begin{array}{r}\text { Printer } \\
\text { Used } \\
\text { Protocols } \\
\text { Packets }\end{array}$ & 党 & 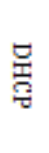 & 语 & $\underset{\Xi}{\Xi}$ & $\overrightarrow{3}$ & $\underset{z}{z}$ & 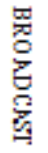 & $\underset{\mathrm{z}}{\mathrm{z}}$ \\
\hline 52 & 0 & 0 & 48 & 0 & 0 & 0 & 4 & 0 \\
\hline 23 & 19 & 0 & 0 & 0 & 4 & 0 & 0 & 0 \\
\hline 1325 & 1265 & 3 & 0 & 2 & 0 & 39 & 16 & 0 \\
\hline 148 & 4 & 1 & 120 & 2 & 0 & 7 & 14 & 0 \\
\hline 146 & 4 & 1 & 120 & 2 & 0 & 6 & 13 & 0 \\
\hline 51 & 0 & 0 & 50 & 0 & 0 & 0 & 1 & 0 \\
\hline 27 & 0 & 0 & 16 & 6 & 4 & 0 & 1 & 0 \\
\hline 0 & 0 & 0 & 0 & 0 & 0 & 0 & 0 & 0 \\
\hline 53 & 0 & 0 & 40 & 6 & 4 & 0 & 3 & 0 \\
\hline 53 & 2 & 0 & 48 & 0 & 0 & 0 & 2 & 1 \\
\hline
\end{tabular}

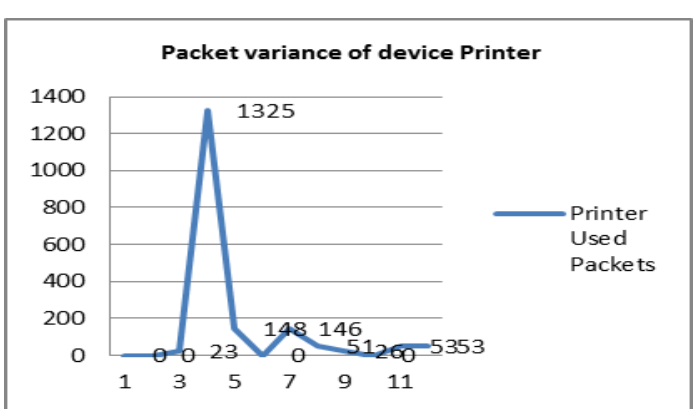

Figure 3 - The protocols used for device printer

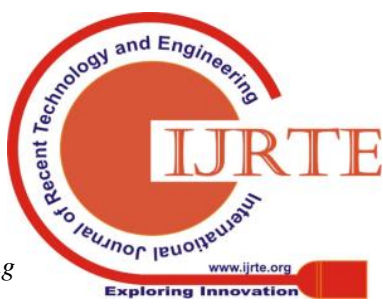


Numerous Observation of the network on a specific time interval shown in the table 4 and fig 4 , the Simple Network Management Protocols (SNMP) shows the involvement of network management. It had to stabilize the network by optimizing the devices those fall in the category of fault implication such as identifying the drivers, service unavailability.

On the other hand the Simple Service Discovery Protocol (SSDP) peaks up to detect the services that needed by the device printers[37],[39],[41]. Though the SSDP involves in the network discovery without the aid of Dynamic Host Configuration Protocols (DHCP) and Domain Name System (DNS) and it is still need to take part in the traffic for maintaining the flaw free network. The NBNS and BROADCAST all have the equal involvement in the network traffic maintenance and to provide quality of services to the end users. This inevitable state is paving the importance of having mechanism that tackle those device printers on the network might be passing through a clouds based services.

\section{CONCLUSION}

The experiment carried out in the real time environment with live traffic of various LAN segment. It is noticed that many devices that take part in the network and provide services to the users. The hybrid network optimization point of view this study gives the importance to the devices that dynamically part to it. The bottlenecks created by the off-hand device printer traffic have been identified through the massive data collected in the sustainable network environment. The network management protocols such as SNMP, NBNS, DHCP and SSDP are identified in this study have mostly spent on optimizing the network. Simple Service Discovery Protocol (SSDP) is hugely supporting the network printers to provide the maximum services requested by the users. The data collected in the network clearly justify that the hybrid network require an amenities from the external cloud based patch services. This study insists the organization to strict to enable those off hand devices service by means of cloud based services [38],[40]

This study can be further enriched to create a prototype of hybrid network patch that is delivered using cloud based services. Also the same type of analysis can be carried out to optimize the wireless devices that are take part in the network dynamically. It can be also considered in the heterogeneous network environment. Also analysing device and providing cloud based optimized solution is challenging in hybrid network infrastructure. The forthcoming study in this field is encouraging and the implementation of cloud based patches could be the next publication

\section{REFERENCES}

[1] Kumaravel A., Rangarajan K.,Algorithm for automaton specification for exploring dynamic labyrinths,Indian Journal of Science and Technology,V-6,I-SUPPL5,PP-4554-4559,Y-2013

[2] P. Kavitha, S. Prabakaran "A Novel Hybrid Segmentation Method with Particle Swarm Optimization and Fuzzy C-Mean Based On Partitioning the Image for Detecting Lung Cancer" International Journal of Engineering and Advanced Technology (IJEAT) ISSN: 2249-8958, Volume-8 Issue-5, June 2019

[3] Kumaravel A., Meetei O.N.,An application of non-uniform cellular automata for efficient cryptography,2013 IEEE Conference on Information and Communication Technologies, ICT 2013,V-,I-,PP-1200-1205,Y-2013

[4] Kumarave A., Rangarajan K.,Routing alogrithm over semi-regular tessellations,2013 IEEE Conference on Information and Communication Technologies, ICT 2013,V-,I-,PP-1180-1184,Y-2013

[5] P. Kavitha, S. Prabakaran "Designing a Feature Vector for Statistical Texture Analysis of Brain Tumor" International Journal of Engineering and Advanced Technology (IJEAT) ISSN: 2249-8958, Volume-8 Issue-5, June 2019

[6] Dutta P., Kumaravel A.,A novel approach to trust based identification of leaders in social networks,Indian Journal of Science and Technology,V-9,I-10,PP--,Y-2016

[7] Kumaravel A., Dutta P.,Application of Pca for context selection for collaborative filtering,Middle - East Journal of Scientific Research,V-20,I-1,PP-88-93,Y-2014

[8] Kumaravel A., Rangarajan K.,Constructing an automaton for exploring dynamic labyrinths,2012 International Conference on Radar, Communication and Computing, ICRCC 2012,V-,I-,PP-161-165,Y-2012

[9] P. Kavitha, S. Prabakaran “Adaptive Bilateral Filter for Multi-Resolution in Brain Tumor Recognition" International Journal of Innovative Technology and Exploring Engineering (IJITEE) ISSN: 2278-3075, Volume-8 Issue-8 June, 2019

[10] Kumaravel A.,Comparison of two multi-classification approaches for detecting network attacks, World Applied Sciences Journal,V-27,I-11,PP-1461-1465,Y-2013

[11] Tariq J., Kumaravel A.,Construction of cellular automata over hexagonal and triangular tessellations for path planning of multi-robots,2016 IEEE International Conference on Computational Intelligence and Computing Research, ICCIC 2016,V-,I-,PP--,Y-2017

[12] Sudha M., Kumaravel A.,Analysis and measurement of wave guides using poisson method,Indonesian Journal of Electrical Engineering and Computer Science,V-8,I-2,PP-546-548,Y-2017

[13] Ayyappan G., Nalini C., Kumaravel A., Various approaches of knowledge transfer in academic social network,International Journal of Engineering and Technology,V-,I-,PP-2791-2794,Y-2017

[14] Kaliyamurthie, K.P., Sivaraman, K., Ramesh, S. Imposing patient data privacy in wireless medical sensor networks through homomorphic cryptosystems 2016, Journal of Chemical and Pharmaceutical Sciences92.

[15] Kaliyamurthie, K.P., Balasubramanian, P.C. An approach to multi secure to historical malformed documents using integer ripple transfiguration 2016 Journal of Chemical and Pharmaceutical Sciences92.

[16] A.Sangeetha,C.Nalini,"Semantic Ranking based on keywords extractions in the web", International Journal of Engineering \& Technology, 7 (2.6) (2018) 290-292

[17] S.V.GayathiriDevi,C.Nalini,N.Kumar,"An efficient software verification using multi-layered software verification tool "International Journal of Engineering \& Technology, 7(2.21)2018 454-457

[18] C.Nalini,ShwtambariKharabe,"A Comparative Study On Different Techniques Used For Finger - Vein Authentication", International Journal Of Pure And Applied Mathematics, Volume 116 No. 82017 , 327-333, Issn: 1314-3395

[19] M.S. Vivekanandan and Dr. C. Rajabhushanam, "Enabling Privacy Protection and Content Assurance in Geo-Social Networks", International Journal of Innovative Research in Management, Engineering and Technology, Vol 3, Issue 4, pp. 49-55, April 2018.

[20] Dr. C. Rajabhushanam, V. Karthik, and G. Vivek, "Elasticity in Cloud Computing", International Journal of Innovative Research in Management, Engineering and Technology, Vol 3, Issue 4, pp. 104-111, April 2018.

[21] K. Rangaswamy and Dr. C. Rajabhushanamc, "CCN-Based Congestion Control Mechanism In Dynamic Networks", International Journal of Innovative Research in Management, Engineering and Technology, Vol 3, Issue 4, pp. 117-119, April 2018.

[22] Kavitha, R., Nedunchelian, R., "Domain-specific Search engine optimization using healthcare ontology and a neural network backpropagation approach", 2017, Research Journal of Biotechnology, Special Issue 2:157-166

[23] Kavitha, G., Kavitha, R., "An analysis to improve throughput of high-power hubs in mobile ad hoc network", 2016, Journal of Chemical and Pharmaceutical Sciences, Vol-9, Issue-2: 361-363

[24] Kavitha, G., Kavitha, R., "Dipping interference to supplement throughput 
in MANET", 2016, Journal of Chemical and Pharmaceutical Sciences, Vol-9, Issue-2: 357-360

[25] Michael, G., Chandrasekar, A.,"Leader election based malicious detection and response system in MANET using mechanism design approach", Journal of Chemical and Pharmaceutical Sciences(JCPS) Volume 9 Issue 2, April - June 2016.

[26] Michael, G., Chandrasekar, A.,"Modeling of detection of camouflaging worm using epidemic dynamic model and power spectral density", Journal of Chemical and Pharmaceutical Sciences(JCPS) Volume 9 Issue 2, April - June 2016

[27] Pothumani, S., Sriram, M., Sridhar, J., Arul Selvan, G., Secure mobile agents communication on intranet,Journal of Chemical and Pharmaceutical Sciences, volume 9, Issue 3, Pg No S32-S35, 2016

[28] Pothumani, S., Sriram, M., Sridhar , Various schemes for database encryption-a survey, Journal of Chemical and Pharmaceutical Sciences, volume 9, Issue 3, Pg NoS103-S106, 2016

[29] Pothumani, S., Sriram, M., Sridhar, A novel economic framework for cloud and grid computing, Journal of Chemical and Pharmaceutical Sciences, volume 9, Issue 3, Pg No S29-S31, 2016

[30] Priya, N., Sridhar, J., Sriram, M. "Ecommerce Transaction Security Challenges and Prevention Methods- New Approach" 2016 ,Journal of Chemical and Pharmaceutical Sciences, JCPS Volume 9 Issue 3.page no:S66-S68

[31] Priya, N.,Sridhar,J.,Sriram, M."Vehicular cloud computing security issues and solutions" Journal of Chemical and Pharmaceutical Sciences(JCPS) Volume 9 Issue 2, April - June 2016

[32] Priya, N., Sridhar, J., Sriram, M. "Mobile large data storage security in cloud computing environment-a new approach" JCPS Volume 9 Issue 2. April - June 2016

[33] Anuradha.C, Khanna.V, "Improving network performance and security in WSN using decentralized hypothesis testing "Journal of Chemical and Pharmaceutical Sciences(JCPS) Volume 9 Issue 2, April - June 2016.

[34] Anuradha.C, Khanna.V, "A novel gsm based control for e-devices" Journal of Chemical and Pharmaceutical Sciences(JCPS) Volume 9 Issue 2, April - June 2016

[35] Anuradha.C, Khanna.V, "Secured privacy preserving sharing and data integration in mobile web environments " Journal of Chemical and Pharmaceutical Sciences(JCPS) Volume 9 Issue 2, April - June 2016.

[36] Sundarraj, B., Kaliyamurthie, K.P. Social network analysis for decisive the ultimate classification from the ensemble to boost accuracy rates 2016 International Journal of Pharmacy and Technology

[37] Sundarraj, B., Kaliyamurthie, K.P. A content-based spam filtering approach victimisation artificial neural networks 2016 International Journal of Pharmacy and Technology83.

[38] Sundarraj, B., Kaliyamurthie, K.P. Remote sensing imaging for satellite image segmentation 2016 International Journal of Pharmacy and Technology8 3.

[39] Sivaraman, K., Senthil, M. Intuitive driver proxy control using artificial intelligence 2016 International Journal of Pharmacy and Technology84.

[40] Sivaraman, K., Kaliyamurthie, K.P. Cloud computing in mobile technology 2016 Journal of Chemical and Pharmaceutical Sciences92.

[41] Sivaraman, K., Khanna, V. Implementation of an extension for browser to detect vulnerable elements on web pages and avoid click jacking 2016 Journal of Chemical and Pharmaceutical Sciences92.

\section{AUTHORS PROFILE}

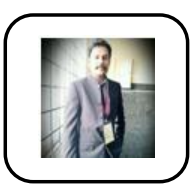

Dr.AR.Arunachalam Associate Professor, Department of Computer Science \& Engineering, Bharath Institute of Higher Education and Research, Chennai, India

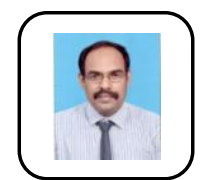

G.Michael Assistant Professor, Department of Computer Science \& Engineering, Bharath Institute of Higher Education and Research, Chennai, India

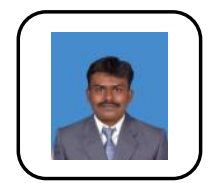

R. Elankavi Assistant Professor, Department of Computer Science \& Engineering, Bharath Institute of Higher Education and Research, Chennai, India 